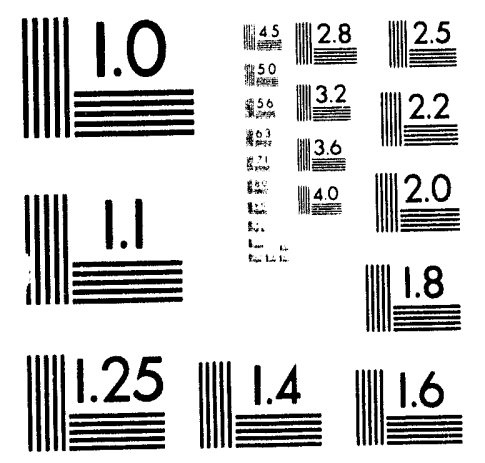



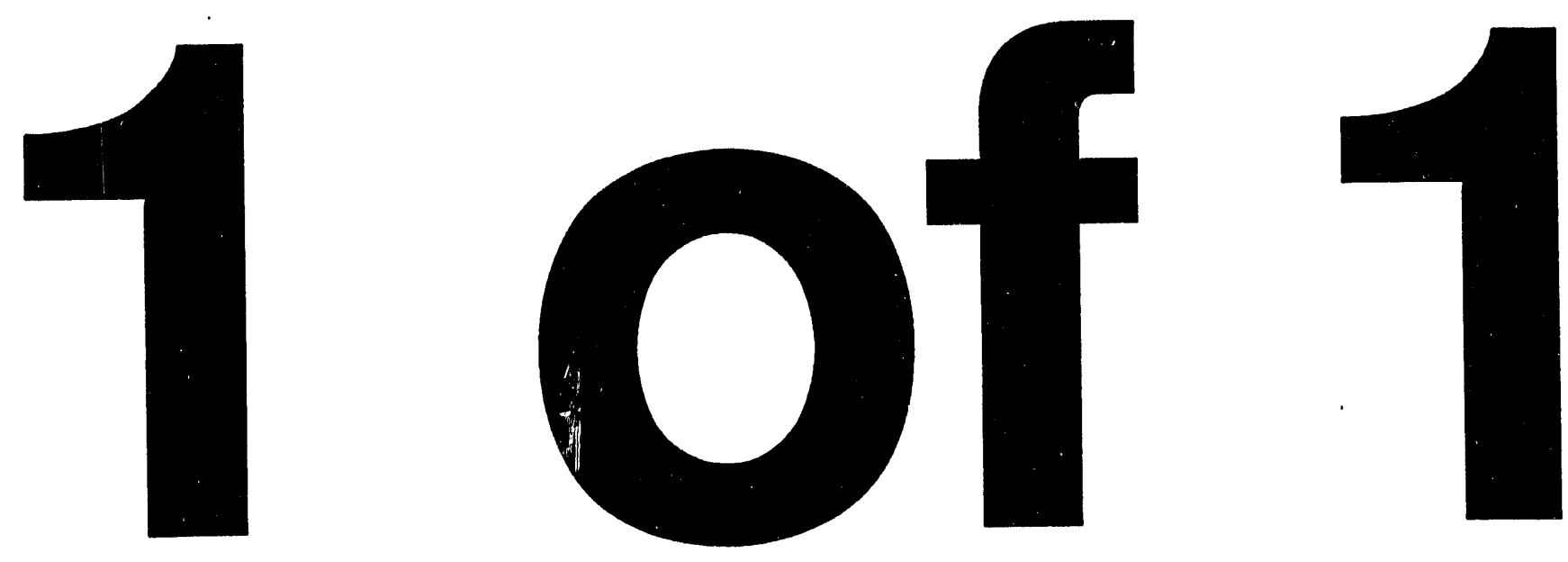
UCRL-JC-114150

PREPRINT

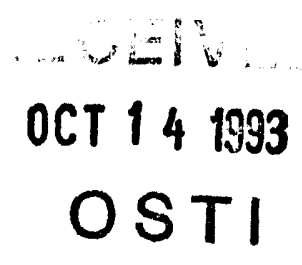

\title{
A SOFT X-RAY PHOTOEMISSION STUDY OF THE CHEMISORPTION AND REACTION OF DIETHYLSILANE ON SI(100)
}

\author{
D.A. Lapiano-Smith \\ F.J. Himpsel \\ L.J. Terminello
}

This paper was prepared for submittal to the 1993 Spring Meeting of the Materials Research Society

San Francisco, CA

April 12-15, 1993

June 1993

This is a preprint of a paper intended forpublication in a journal or proceedings. Since changes may be made before publication, this preprint is made available with the understanding that it will not be cited or reproduced without the permission of the author.

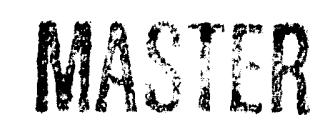




\section{DISCLAIMER}

This documeat was meparsd as an account of work spossored by an agency of the United States Government. Neither the United States Government mor the University of California nor any of stheir employees, makes any warranty, express or implied, of assumes any lezal liability or responsibility for the acruncy, completemesa, or usefulmess of any information, apparatus, product, or procesa disclosed, of represeats that its use would not infringe privately ewned rights. Reference hereia to any epectific

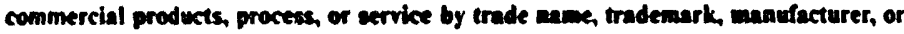
otherwise, does nor meresserily constitute or imply its emdorsement, recomenendation. or favoring by the United Stales Goverameat or the University of Califoraia. The viens and opinions of authors expressed berein do mot mecessarily stacte or reflect those of the United Stutes Government or the University of Californim, and shall not be used for advertising or product endorsemenc purposes. 


\title{
A SOFT X-RAY PHOTOEMISSION STUDY OF THE CHEMISORPTION AND REACTION OF DIETHYLSILANE ON SI(100)
}

D. A. LAPIANO-SMITH, F. J. HIMPSEL AND L. J. TERMINELLO*

IBM, Thomas J. Watson Research Center, Yorktown Heights, N.Y. 10598

'Lawrence Livermore National Laboratory, Livermore, CA 94550

\begin{abstract}
Soft $\mathrm{x}$-ray synchrotron radiation has been utilized as the excitation source in a high-resolution photocmission experiment designed to investigate the chemisorption and subsequent reaction of diethylsilane on the technologically important $\mathrm{Si}(100)$ surface. We have found that diethylsilane chemisorbs dissociatively to form $\mathrm{Si}-\mathrm{CH}_{2} \mathrm{CH}_{3}$ surface species on $\mathrm{Si}(100)$ following a room temperature exposure. These species are identified by two very sharp peaks observed in the valence band spectra positioned at 17.9 and $14.3 \mathrm{eV}$ binding energy. In addition, $\mathrm{C} 1 \mathrm{~s}$ core level spectra, measured following exposures of $\mathrm{Si}(100)$ substrates as a function of surface temperature, show that Carbon, in some form, exists on the Si surface following exposures at every temperature from room temperature to about $600{ }^{\circ} \mathrm{C}$. While only $-\mathrm{CH}_{2} \mathrm{CH}_{3}$ ethyl groups are observed on the surface at room temperature, these species appear to partially dehydrogenate at $300^{\circ} \mathrm{C}$, producing a mixture of $-\mathrm{CH}_{2} \mathrm{CH}_{3}$ groups and other intermediate carbonaceous species. At a growth temperature of about $400^{\circ} \mathrm{C}$ the intermixing of elemental Carbon with Si begins. At higher temperatures, we observe the continued degradation of diethylsilane to produce a $\mathrm{Si}+\mathrm{C}$ alloy on the surface at $600^{\circ} \mathrm{C}$. Our results indicate that diethylsilane has potential as a molecular precursor for $\mathrm{SiC}$ formation by chemical vapor deposition techniques.
\end{abstract}

\section{INTRODUCTION}

The outstanding characteristics of synchrotron radiation, for example, its high brightness, large encrgy range and tunability to name a few, highlight it as an attractive excitation source for core level and valence band photoemission spectroscopic investigations. Specifically, the ability to tune the radiation into monochromatic photons has underscored the high surface sensitivity of soft $x$-ray photoemission spectroscopy as a probe of surface chemical species and their vicinal atomic constituents.- In addition, this technique can be utilized to monitor the molecular decomposition of chemical vapor deposition (CVD) precursors on various surfaces.

We report the results of a high resolution soft $x$-ray photoemission investigation that was designed to probe the chemisorption and subsequent reaction of Dicthylsilane (DES) on Silicon (100). DES has been considered recently as a possible molecular precursor for Silicon deposition [1] in group IV atomic layer epitaxy (ALE) growth processes. Interest in this candidate arises in part from the fact that alkylsilanes are less toxic and flammable than Silicon hydrides and halohydrides. In light of this, the main objective of this investigation has been to determine whether or not there exist a low temperature growth regime in which Silicon, from the decompositon of DES, can be deposited on a $\mathrm{Si}(100)$ surface without the codeposition of Carbon. Alternatively, the observation of Carbon would suggest the potential use of DES as a source for the formation of Silicon Carbide (SiC).

Valence band photoemission data were measured to examine the changes in the clectronic structure of the Silicon (100) surface and to characterize the surface species formed following the room temperature chemisorption of DES and subsequent reactivity at higher surface temperatures. We show that DES chemisorbs dissociatively to form Si- $\mathrm{CH}_{2} \mathrm{CH}_{3}$ surface species on $\mathrm{Si}(100)$ at room temperature. These species are identified by a prominent doublet feature observed in the valence band spectra with peak positions at 17.9 and $14.3 \mathrm{cV}$ binding encrgy. Anneals of the (100) surface to a temperature of $350^{\circ} \mathrm{C}$ promotes the onset of desorption of the ethyl group from the surface. This feature, although decreasing in intensity continues to persist until a tempcrature of $550^{\circ} \mathrm{C}$ is attained. At this temperature, the remaining $-\mathrm{CH}_{2} \mathrm{CH}_{3}$ species dissociate to form Si-C surface species.

Si $2 p$ and $C$ is core level photoelectron spectra were mcasured following exposures of the $\mathrm{Si}(100)$ substrates as a function of surface temperature. Si $2 p$ data however, will not be shown here but are presented in another report. [2] C 1s data show that Carbon, in some form, cxists on the Silicon surface following exposures at every temperature from room temperature to where $\mathrm{SiC}$ is known to form (above $600^{\circ} \mathrm{C}$ ) by hydrocarbon decomposition [3]. While one sees only $-\mathrm{CH}_{2} \mathrm{CH}_{3}$ ethyl groups on the surface at room temperature, these species appear to partially dehydrogenate at $300{ }^{\circ} \mathrm{C}$, producing a mixture of $-\mathrm{CH}_{2} \mathrm{CH}_{3}$ groups and other intermediate carbonaceous species. At a growth temperature of about $400^{\circ} \mathrm{C}$ the intermixing of elemental Carbon with Si begins. At higher temperatures, we observe the continued degradation of DES to produce a $\mathrm{Si}+\mathrm{C}$ alloy on the surface at $600^{\circ} \mathrm{C}$. 
Clean Silicon (100) substrates were preparcd by direct ohmic heating $101050^{\circ} \mathrm{C}$ in a preparation chamber maintaincd at a base pressure of $2 \times 10^{-10}$ Torr. Exposures of the substrates to DES were completed in an adjacent dosing chamber with a base pressure of $5 \times 10^{-10}$ Torr. DES was passed through a liquid $\mathrm{N}_{2}$ trap before being introduced into the UHV chamber through a sapphire leak valve. Exposures requiring a substrate temperature greater than ambient temperature were conducted as follows. While in the dosing chamber, the substrate was ohmically heated to the desired temperature. The source gas was then bled into the chamber until the desired pressure was attained and held for some predetermined duration of time. Following the evacuation of the gas to a chamber pressure better than $5 \times 10^{-9}$ Torr, the heat source was terminated. The sample was transferred via a UHV manipulator transfer system, to the spectrometer for analysis. The base pressure of the spectrometer was 1 $\times 10^{-10}$ Torr. All substrate anneals subscquent to the dosing were performed without sample repositioning.

Soft $x$-ray photoemission spectra were obtained at the U8B beamline of the National Synchrotron Light Source at Brookhaven National Labortory. Valence band and core level photoclectron spectra were obtained following excitation of the substrates with synchrotron radiation. An angle-integrating, display type electron spectrometer [4], coupled to a $6 \mathrm{M}$ and $10 \mathrm{M}$ toroidal grating monochromator, was used to encrgy analyze the resultant photoelectrons. Photons of $55 \mathrm{eV}$ were utilized to measure the valence band structure of the clean and DES-exposed Silicon surfaces. Monochromatic photons in the energy range between 130 and $330 \mathrm{eV}$ were used to excite the core electrons of the $\mathrm{Si} 2 \mathrm{p}$ and $\mathrm{C}$ 1s levels. The $\mathrm{Si} 2 \mathrm{p}$ and $\mathrm{C}$ 1s spectra were obtained with a convoluted instrumental resolution of approxirnately 0.2 and $0.3 \mathrm{eV}$, respectively.

\section{RESULTS_and DISCUSSION}

\section{A) Valence Band Phatoelectron Spectroscopy}

Figure 1 shows valence band spectra for $\mathrm{Si}(100)$. These data probe the changes in the electronic structure of the clean surface following the dissociative chcmisorption of DES at room. temperature and subsequent anneals of the prepared surface to temperatures above $650^{\circ} \mathrm{C}$. These data are presented on a binding energy scale referenced to $E_{f}=0 \mathrm{eV}$. Fig. 1 pancl a, displays the valence band spectrum of a clcan $\mathrm{Si}(100)$ surfacc as a dotted line. The surface shown as a solid line results from a saturation coverage of the clcan substratc following a 300 Langmuir (L) DES exposure at room temperature.

The spectrum shown as the solid line has changed dramatically from that observed for the clcan surface (dotted line). Two very sharp peaks appear at 17.9 and $14.3 \mathrm{eV}$ below $E_{\mathrm{f}}$. These peaks are the signature for the chemisorption of $-\mathrm{CH}_{2} \mathrm{CH}_{3}$ ethyl groups on the surface. When referenced to the vacuum level these fcatures appear at binding energies in excellent agreement with the gas phase XPS spectra reported previously by Hamrin et. al. [5] and Pireaux et. al. [6]. Hamrin et. al. [5] assigned the split peaks at 23.9 and $20.3 \mathrm{eV}$ to the $2 \mathrm{a}_{1 \mathrm{~g}}$ and $2 \mathrm{a}_{2 \mathrm{a}}$ orbitals of ethane. The observed $3.6 \mathrm{eV}$ energy splitting between the two peaks shown in Figure 1 is identical to the experimental splitting reported by Hamrin et. al. [5]. This doublet feature is similar to that identified previously by Pireaux et. al. [6] in the gas phase photoelectron spectra of the simple alkanes $\left(\mathrm{C}_{x} \mathrm{H}_{2 x+2}\right)$ where, in general, for a string a $\mathrm{N}$ carbon atoms one expects an $\mathrm{N}$-fold splitting of the $\mathrm{C} 2 \mathrm{~s}$ line. In ethane, [12,13] the single molecular orbital observed for methane is split into two bonding and two antibonding levels.

Panel $b$ in Figure 1 shows only slight changes in the clectronic structure following an anneal of the saturated surface to $350^{\circ} \mathrm{C}$. It appears that the $-\mathrm{CH}_{2} \mathrm{CH}_{3}$ groups begin to desorb from the surface, and as a result, all associated features decrease in intensity, as observed by comparison with the Si associated feature at the valence band maximum. Further annealing of the sample to 400 and $500^{\circ} \mathrm{C}$ (not shown) promotes the continued desorption of the $-\mathrm{CH}_{2} \mathrm{CH}_{3}$ groups. All features associated with DES chemisorption have significantly decreased in intensity, yet the doublet peaks at higher binding energy still persist with no indication of $-\mathrm{CH}_{3}$ or $-\mathrm{CH}_{2}$ species developing. This observation is indicative of the desorption of $-\mathrm{CH}_{2} \mathrm{CH}_{3}$ groups from the surface and precludes the dissociation of the alkane chain into methyl $\left(-\mathrm{CH}_{3}\right)$ or $\mathrm{CH}_{\mathrm{x}}$ surface species. Surcly if the dominate reaction pathway was the dissociation of $-\mathrm{CH}_{2} \mathrm{CH}_{3}$ to form surface $-\mathrm{CH}_{3}$ species, a very prominent, single peak would be expocted 10 appear between the two ethyl peaks at a binding energy of about $23.1 \mathrm{eV}$ [5.6] $(17.1 \mathrm{eV}$ on our energy scale, when referenced to $E_{f}$ ).

A subsequent anneal of the surface to $550^{\circ} \mathrm{C}$ produces significant changes in the valence band spectrum as shown in Fig. 1, panel c. The doublet feature associated with ethyl groups bonding to the surface has completely disappeared. However, a weak, broad feature has become visible at a binding energy of $15.3 \mathrm{eV}$. The energy position of this feature is in close agreement with that reported by Didziulis et. al. [7] for Silicon bound to elemental Carbon in $\alpha \mathrm{SiC}$. The persistent feature at a binding energy of $7 \mathrm{eV}$ also has been observed previously in the photoelectron spectrum of $\alpha \mathrm{SiC}$ that has been measured following irradiation of the surface with $50 \mathrm{eV}$ photons. This feature has been assigned by Didziulius et. al [7] to photocmission from a dominant $C 2 p$ based valence level. At $55 \mathrm{eV}$ photon energy the theoretical photoionization cross section for the $\mathrm{C} 2 \mathrm{p}$ and $2 \mathrm{~s}$ are significantly greater than that of the Si valence band [8] thus precluding the quantification of surface Silicon monohydride contributions to the valence band intensity. 
Further anneals of the surface to temperatures of 600 and $700^{\circ} \mathrm{C}$ (not shown) complcte the reaction process. There are no observable features in the valence band spectra that can be associated with Si-C or Si-H bonding. An anneal of the surface to $800^{\circ} \mathrm{C}$ promotes the formation of the surface state at about $1.1 \mathrm{eV}$ and resembles the spectrum for the clean $\mathrm{Si}(100)$ surface shown as the dotted line in Figure 1 panel a. Although the surface appears to be quite clean it is believed that Si has diffuscd out from the bulk to cover the surface Carbon, while the elemental Carbon aggregates into SiC crystallites below the Si surface. This chemical process has been observed previously by Bozso et al [3] for $\mathrm{SiC}$ growth following $\mathrm{C}_{2} \mathrm{H}_{4}$ cxposure to $\mathrm{Si}(100)$.

\section{B) Core Level_Photoelectran_Spectroscapy}

The results of the valence band photoemission measurements indicated that there may be a range of temperatures where coadsorbed $-\mathrm{C}_{2} \mathrm{H}_{n}$ species can be desorbed from the surface leaving behind $\mathrm{Si}$ and a minimal amount of elemental carbon. In this section the results obtained from $C$ is core level spectra will be discussed which probe the surface chemistry more quantitatively than valence band results. The $C$ is core level photoemission features were monitored following 500L exposures of the surface to DES as a function of substrate tcmperature.

Figure 2 shows a series of $\mathrm{C} 1 \mathrm{~s}$ photoemission spectra measured following exposures of $\mathrm{Si}(100)$ to DES at substrate temperatures ranging from ambient room temperature (pancl a) to $600^{\circ} \mathrm{C}$ (panel d). These spectra allow one to distinguish the Carbon surface species formed within this temperature regime. Panel a in Fig. 2 shows the result of exposing a clean $\mathrm{Si}(100)$ surface to $500 \mathrm{~L}$ DES at room temperature. We know from the valence band data (Figure 1) obtained following a room temperature exposure that DES dissociatively chemisorbs to produce $\mathrm{Si}-\mathrm{CH}_{2} \mathrm{CH}_{3}$ as the dominant surface species. We can conclude that the $\mathrm{C} 1 \mathrm{~s}$ core level spectrum shown in panel a is representative of $-\mathrm{CH}_{2} \mathrm{CH}_{3}$ ethyl groups bonding to the $\mathrm{Si}(100)$ surface. The $\mathrm{C}$ is feature, positioned at 45.0 $\mathrm{eV}$ kinetic energy, has been fil with a least squares procedure to a single Gaussian lineshape with a FWHM of 1.7 $\mathrm{eV}$. When placed on a binding energy scale, this feature approaches a binding energy close to that expected for hydrocarbon species [9].

The $C 1$ spectrum in panel $2 b$ was measured following the exposure of a clean $\mathrm{Si}(100)$ surface to $500 \mathrm{~L}$ DES at a substrate temperature of $300^{\circ} \mathrm{C}$. Clearly, the Carbon peak has shifted by about $0.4 \mathrm{eV}$ to higher kinetic energy (lower binding energy) relative to that observed in panel a. In addition, the shape of the peak has become asymmetric on the high kinetic energy side. This suggests that the $\mathrm{C}$ ls photoemission peak is actually a superposition of at least two chemical components arising from $\mathrm{Si}-\mathrm{CH}_{2} \mathrm{CH}_{3}$ and other carbonaccous surface species. While it may be possible that graphite (binding encrgy, $284.7 \mathrm{eV}$ ) [10] and/or diamond-like (285.0 eV) [11] moieties may form on the $\mathrm{Si}(100)$ surface at elevated temperatures, it can be inferred that the shifting $\mathrm{C}$ 1s feature may be due in part to the dehydrogenation of the $-\mathrm{CH}_{2} \mathrm{CH}_{3}$ adsorbate. The lack of sharpness in this $\mathrm{C}$ 1s spectrum precludes fitting the data thereby limiting the ability to identify the chemical components of the $\mathrm{C}$ is feature.

Panel $c$ in Figure 2 depicts the continued shift of the $C$ 1s photoemission feature to lower binding energy following an exposure at an increased surface temperature. The spectrum in panel $c$ results following an exposure at $400^{\circ} \mathrm{C}$ and depicts a shift of the peak position of about $0.9 \mathrm{eV}$ relative to that observed in pancl a. A $600{ }^{\circ} \mathrm{C}$ exposure (panel d) causes the $\mathrm{C} 1 \mathrm{~s}$ feature to shift a total of $1.8 \mathrm{eV}$ to higher kinetic energy (lower binding energy) with respect to that observed in panel a. This is accompanied by an intensity increase at the binding energy $[9,12,13]$ expected for Carbon in SiC formation. In addition, the $\mathrm{C}$ 1s fcature has sharpened considerably and has been accurately fit with a least squares procedure to a single Gaussian lineshape with a FWHM of $1.5 \mathrm{eV}$. These effects indicate the completion of the surface reaction to reduce the various hydrocarbon species to clemental Carbon on the Si surface. In addition, the results are in qualitative agreement with that reported by Bozso et. al [3] for CVD SiC formation following the exposure of $\mathrm{Si}(100)$ to $\mathrm{C}_{2} \mathrm{H}_{4}$. Bozso et. al [3] show threc temperature regimes for $\mathrm{SiC}$ film growth. In the temperature range between $577^{2} 10^{\circ} 667^{\circ} \mathrm{C}$ a surface reaction proceeds to form a $\mathrm{Si}+\mathrm{C}$ alloy. Only above $667^{\circ} \mathrm{C}$ does crystalline $\mathrm{SiC}$ film formation commence with concomitant diffusion processes in the bulk to form a thin Si surface overlayer.

\section{CONCUUSIONS}

We have used soft $x$-ray photoemission spectroscopy to examine the surface chemistry involved in the reaction between DES and Si(100). Two sharp peaks observed in the valence band spectra at 17.9 and $14.3 \mathrm{cV}$ binding energy serve to "fingerprint" the existence of $\mathrm{Si}-\mathrm{CH}_{2} \mathrm{CH}_{3}$ surface species, which result from the dissociative chemisorption of DES following a room temperature exposure. The distinct doublet is a result of the chemical interaction between the Iwo $\mathrm{C}$ atoms in the alkyl chain to produce bonding and antibonding combinations of the $\mathrm{C} 2 \mathrm{~s}$ states. Annealing the (100) surface to a temperature of $350^{\circ} \mathrm{C}$ promotes the onset of desorption of the $-\mathrm{CH}_{2} \mathrm{CH}_{3}$ groups from the surface. At a temperature of $550^{\circ} \mathrm{C}$, the remaining $-\mathrm{CH}_{2} \mathrm{CH}_{3}$ species dissociate to form Si-C surface species.

C 1 s core level photoelectron spectra measured following exposures of the $\mathrm{Si}(100)$ substrates to DES as a function of surface temperature reveal that Carbon, in some form is deposited on the Silicon surfaces following exposures at all temperatures examined from the ambient $10600^{\circ} \mathrm{C}$. However, the asymmetry observed in the $\mathrm{C}$ is core level spectra measured above room temperature reveal the presence of $-\mathrm{CH}_{2} \mathrm{CH}_{3}$ groups as well as a mixture 
of $-\mathrm{CH}_{2} \mathrm{CH}_{3}$ decomposition products that are not discernible in the valence band spectra. Whilc one observes only $-\mathrm{CH}_{2} \mathrm{CH}_{3}$ ethyl groups on the surface at room temperature, these species appear to partially dehydrogenate above $300^{\circ} \mathrm{C}$, producing a mixture of $-\mathrm{CH}_{2} \mathrm{CH}_{3}$ groups and other carbonaceous species. At a growth temperature of about $400^{\circ} \mathrm{C}$ some DES has completely decomposed to leave elemental C on the Si surface. C 1s data obtained following a $600^{\circ} \mathrm{C}$ exposure indicates that the complete thermal degradation of DES serves as an efficient source of elemental $\mathrm{C}$ for the formation of a $\mathrm{Si}+\widetilde{Z}$ alloy layer on the semiconductor surface. While low-temperature Si ALE may be feasible with DES, provided that some mechanism can be employed to remove all surface carbon, our results indicate clearly that DES has greater potential as a candidate for SiC formation by CVD techniques at temperatures above the alloying point.

\section{ACKNOWLEDGEMENT}

This work was supported by the Office of Naval Research. Experimental investigations were carried out at the National Synchrotron Light Source, Brookhaven National Laboratory, which is supported by the U.S. Department of Energy. This work was also conducted partly under the auspices of the U.S. Department of Energy by the Lawrence Livermore National Laboratory under contract \#W-7405-ENG-48. The DES was obtained from the J.C. Schumacher Company.

\section{REEERENCES}

1. P.A. Coon, M.L. Wise, A.C. Dillon, M.B. Robinson and S.M. George, J. Vac. Sci. Technol. B10, 221 (1992).

2. D.A. Lapiano-Smith, F.J. Himpsel and L.J. Terminello, J. Appl. Physics, submitted.

3. F. Bozso, J.T. Yates, Jr., WJ. Choyke and and L. Muchlhoff, J. Appl. Phys., 57, 2771 (1985).

4. D.E. Eastman, J.J.Donelon, N.C. Hein and FJ. Himpsel, Nucl. Instrum. Methods 172, 327 (1980).

5. K. Hamrin, G. Johansson, U. Gelius, A. Fahiman, C. Nordling and K. Siegbahn, Chem. Phys. Letl. 1, 613 (1968).

6. J.J. Pireaux, J. Riga, P.A. Thiry, R. Caudano and J.J. Verbist, Physica Scripta, T13, 78 (1986).

7. S.V. Didziulis, J.R. Lince, P.D. Fleischauer and J.A. Yarmoff, Inorg. Chem. 30, 672 (1991).

8. J.J. Yeh and I. Lindau, Al. Data Nucl. Data Tables, 32, 1 (1985).

9. S. Contarini, S.P. Howlett, C. Rizzo and B.A. DeAngelis, Appl. Sur. Sci. 51, 177 (1991).

10. F.R. McFeely, S.P. Kowalczyk, L.Ley, R.G. Cavell, R.A. Pollak and D.A. Shirley, Phys. Rev. B9, 5268 (1974).

11. J.F. Morar, FJ. Himpsel, G. Hollinger, J.L. Jordan, G. Hughes and F.R. McFeely, Surf. Sci.

12. K. Miyoshi and D.H. Buckley, Appl. Surf. Sci. 10, 357 (1982).

13. L. Muehlhoff, W.J. Choyke, M.J. Bozack and J.T. Yates, Jr., J. Appl. Phys. 60, 2842 (1986).

\section{FIGURECARTIONS}

Figure 1: Panel a) Valence band spectrum of a clean $\mathrm{Si}(100)$ surface (dotted line) and the spectrum (solid line) indicating a saturation coverage following the exposure of the clean surface to $300 \mathrm{~L}$ DES at room temperature. The two very sharp peaks at 17.9 and $14.3 \mathrm{eV}$ below $\mathrm{E}_{\mathrm{femi}}$ (solid line) are the signature for the chemisorption of $-\mathrm{CH}_{2} \mathrm{CH}_{3}$ ethyl groups on the surface. b) results following an anneal of the prepared surface in (a) to $\left.350^{\circ} \mathrm{C}, \mathrm{c}\right)$ results following an anneal to $550^{\circ} \mathrm{C}$.

Figure 2: A series of $\mathrm{C}$ 1s photoemission spectra measured following exposures of $\mathrm{Si}(100)$ to $500 \mathrm{~L}$ DES at various substrate temperatures: a) ambient room temperature, b) $\left.300^{\circ} \mathrm{C}, \mathrm{c}\right) 400^{\circ} \mathrm{C}$, and d) $600^{\circ} \mathrm{C}$. 


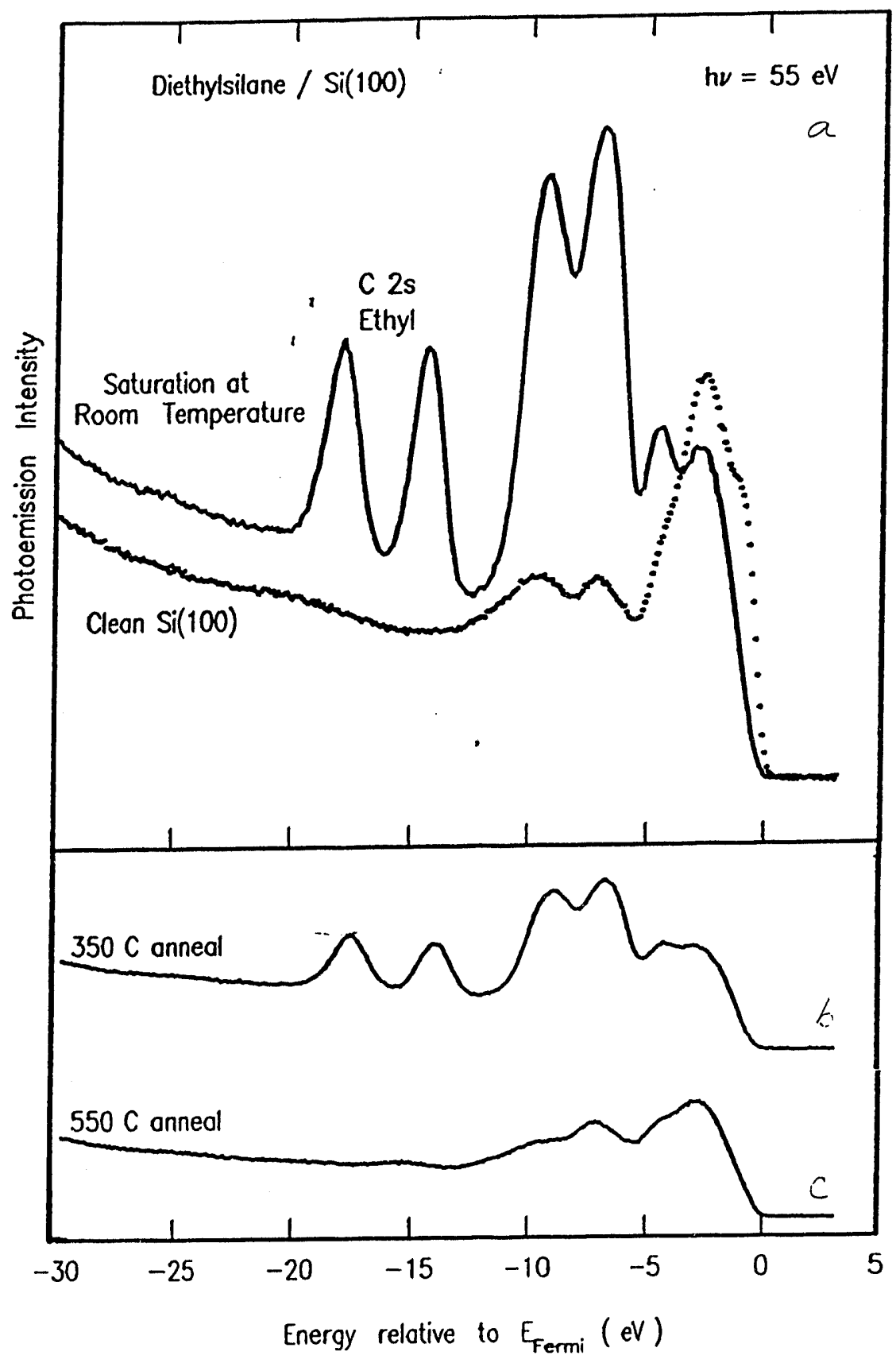

7 in 1 


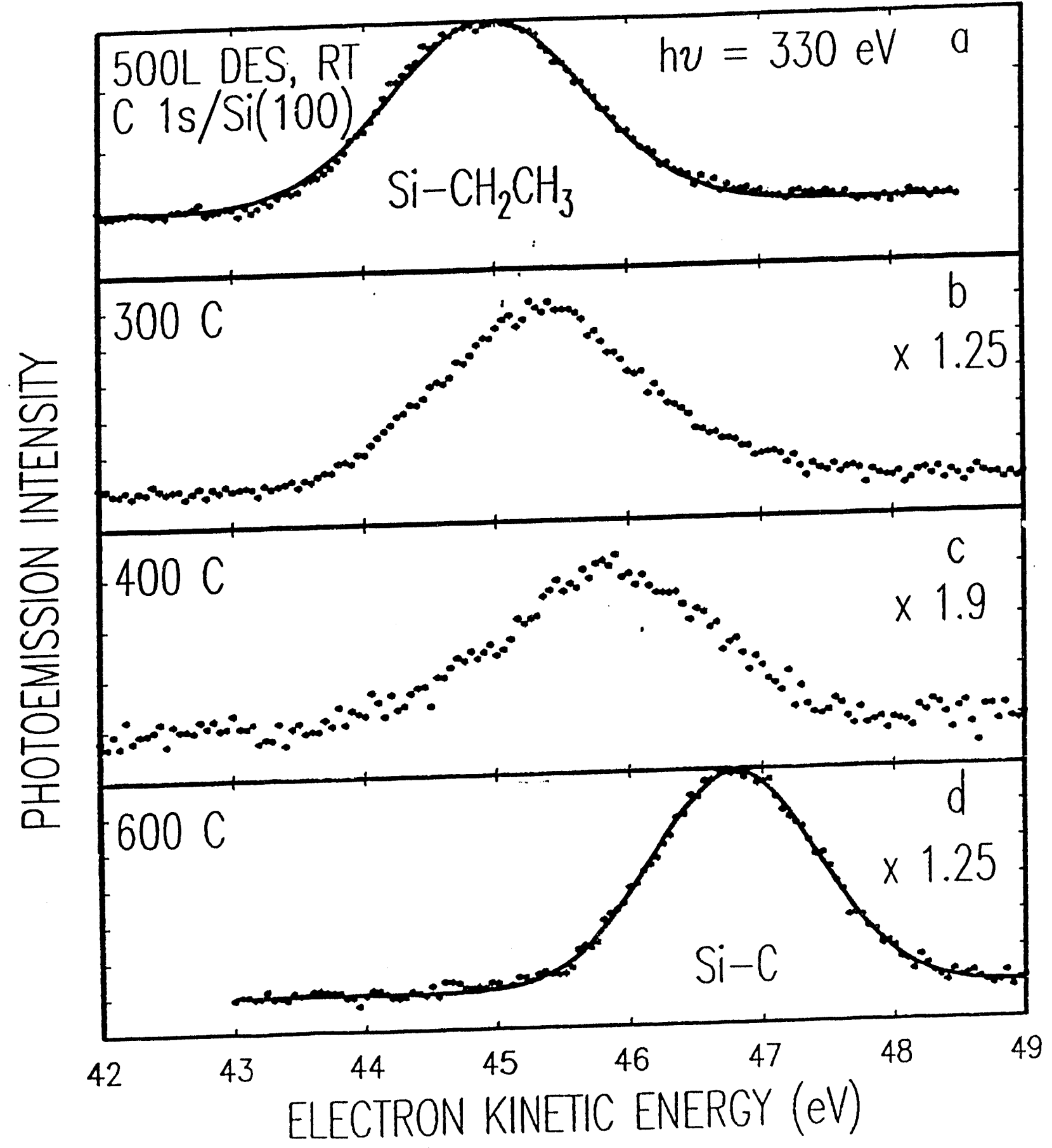

7 in 2 

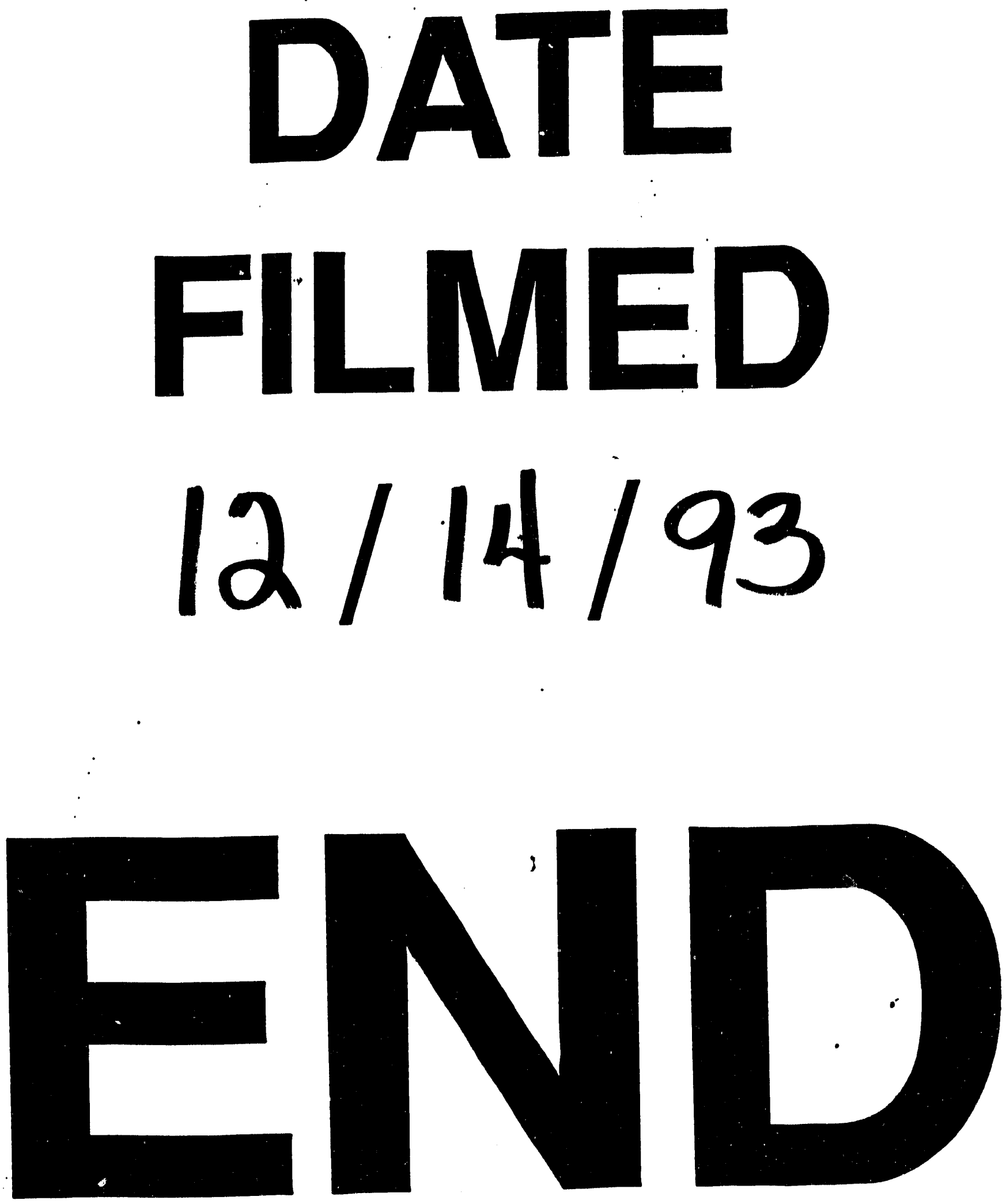
